\title{
A NOVA REGULAÇÃO PRÓ-CONCORRÊNCIA: A INSERÇÃO DA CONCORRENCIA EM SETORES REGULADOS
}

\section{NEW PRO-COMPETITIVE REGULATION: THE INSERTION OF COMPETITION IN REGULATED SECTORS}

\author{
Marcelo Bodoco" \\ Elve Miguel Cenci*
}

\begin{abstract}
Resumo: Este artigo desenvolve a nova regulação estatal pós-reforma do Estado dos anos de 1990, cuja regulação estatal passa a ser conforme o mercado. Será discutida a inserção da concorrência em setores que foram trespassados aos particulares. Para tanto, desenvolve a noção de interesse público na contemporaneidade, noção imprescindível para o estudo dos fundamentos da regulação. Desenvolve, também, os fundamentos da regulação no contexto da reforma do Estado dos anos 90. Analisa a noção de serviço público econômico que é objeto de estudo do presente artigo. Analisa também que os serviços públicos econômicos não são incompatíveis com a livre concorrência e com o lucro. Por fim, demonstra que a atividade regulatória estatal, por meio de seus órgãos, deve ser proporcional. Demonstra que a proporcionalidade, que deve guiar a hermenêutica do art. 170, da CF, coloca em sua balança o princípio da defesa da concorrência e os objetivos dos serviços públicos.
\end{abstract}

Palavras-chave: Interesses Públicos; Serviços Públicos; Regulação Estatal; Proporcionalidade.

Abstract: This paper develops a new regulation that resulted after the state reform in the 1990s, where regulation is to promote competition. Develops the notion of public interest in contemporaneity, whose concept is essential for the study of the foundations of regulation. Develops the fundamentals of regulation in the context of state reform in the $90 \mathrm{~s}$. Analyses the economic concept of public service that will be studied in this article. Analyses that public services are not incompatible with economic freedom and with profit. Finally, demonstrates that the state regulatory activity through its organs should be proportional. Demonstrates that the proportionality, that should guide the hermeneutics of art. 170 of the Constitution, put in equilibrium the principle of antitrust and objectives of public services.

Key-words: Public Interests; Public Services; Government Regulation; Proportionality.

Graduado pela Universidade Estadual de Londrina. Especialização em Direito do Estado pela Universidade Estadual de Londrina. Mestrando em Direito Negocial pela Universidade Estadual de Londrina. Email: mbodoco@yahoo.com.br.

Doutor em Filosofia pela UFRJ. Professor do programa de mestrado em Direito Negocial. Email: elve@uel.br. 


\section{INTRODUÇÃO}

Este artigo tem por objetivo analisar a nova regulação estatal que se originou com o processo de reforma do Estado dos anos de 1990, em que a regulação passa a ser no sentido de inserir valores concorrenciais em setores onde há a prestação de serviço público.

Para isso se faz necessário perpassar por alguns institutos que tiveram suas noções alteradas, quais sejam: as noções de interesse público e de serviço público. Demonstrar-se-á que a contemporaneidade é marcada por uma multiplicidade de interesses públicos. Em meio a esta fragmentação cabe ao Estado o papel de mediador de tais interesses que se encontram na sociedade. Será analisado, consequentemente, que uma das maneiras de se institucionalizar a mediação do Estado com a sociedade é por meio de autoridades reguladoras independentes. Com relação aos serviços públicos, cuja noção é imprescindível à correta compreensão do objetivo deste artigo, estes passaram por uma mudança de concepção quando do processo de reforma do Estado ocorrido nos anos de 1990. A título de prévia compreensão, os serviços que antes estavam sob monopólio estatal foram alçados a serviços públicos econômicos. A compreensão que hoje ilumina esta categoria de serviços públicos é que tais atividades não são incompatíveis com o lucro, razão pela qual são classificadas como atividades econômicas em sentido amplo, na sistematização de Eros Grau.

Em momento posterior será discutida brevemente a intensidade de inserção de valores concorrenciais em setores regulados. Uma observação importante para a correta compreensão deste artigo é que o termo regulação que será utilizado se refere tão somente a regulação de serviços públicos trespassados a particulares. Então, com relação à intensidade regulatória, a questão que irá se colocar é até que ponto pode ser sacrificado o valor concorrencial nestes setores. Essa questão tem importância, pois a ordem econômica mundo do deve ser é informada pelos valores do art. 170 da Constituição Federal, e um dos princípios da ordem econômica é a defesa da concorrência. Mas o objetivo proposto neste artigo ganha complexidade porque não se está a analisar a concorrência no regime de mercado propriamente dito. Aqui será suscitada uma problemática, ou seja, de um lado a defesa do valor concorrencial e de outro os objetivos dos serviços públicos.

Num último momento deste artigo será evocada a proporcionalidade para a otimização dos princípios que orientam a ordem econômica. Será demonstrado que a atividade estatal deve ser uma atividade proporcional. A correta hermenêutica dos valores do art. 170 da Constituição Federal deve ser no sentido que lhes confiram maior eficácia possível. 


\section{OS INTERESSES PÚBLICOS: A NOÇÃO NA CONTEMPORANEIDADE}

Será analisada neste item a noção de interesse público na contemporaneidade, e para isso serão utilizados os ensinamentos de Floriano Peixoto de Azevedo Marques Neto.

No seio do Estado contemporâneo o poder político ganha uma nova roupagem face algumas transformações econômicas, sociais e políticas. $\mathrm{O}$ Estado Moderno se sustentou sobre alguns pilares que passaram por um processo de reconfiguração, basicamente estes pilares são a unicidade do poder estatal, a noção de soberania forte e a homogeneidade da sociedade. Contudo, houve uma reconfiguração dos pressupostos que sustentaram a modernidade estatal. Segundo Marques Neto (2002, p. 104), os fatores da relativização dos pressupostos do Estado Moderno são: “(a) a globalização econômica, que assume papel relevante nos anos 90, e (b) o processo de complexização e fragmentação social, impulsionado a partir dos anos $70 . ”$

$\mathrm{O}$ que se pretende neste item, segundo os ensinamentos de Marques Neto (2002), é que a imperatividade e a coercibilidade normativas do Estado perdem força que se sucumbem às forças sociais e econômicas encontradiças na sociedade global. Aqui se está diante da força do poder econômico no seio da globalização. Há também que evocar, Segundo Marques Neto (2002), o Direito Internacional, o qual se expande e traz consigo a diminuição do caráter autoritário do Direito na modernidade. O Estado começa a ter seus pressupostos implodidos pela internacionalização e seus reflexos na sociedade global, ou seja, isso significa que são transformações globais e econômicas que alteram o Estado.

Vale a pena citar também outro processo que contribui para a relativização dos referidos pressupostos. Este ocorre no seio social do Estado Nacional. Para Marques Neto (2002), a construção da modernidade política repousou na idéia da homogeneidade social e também na idéia de um centro decisório que refletisse esse interesse geral. Aqui a questão chave é a homogeneidade social que passou por um processo de fragmentação.

Como esclarecimento, o todo social homogêneo era a característica do Estado Moderno e sobre este todo social o poder decisório exprimia o que era interesse geral. Segundo o entender de Marques Neto (2002), essa sociedade uniforme vai se fragmentando e fugindo à estrutura institucional e aos mecanismos de representação tradicionais. Referido processo de fragmentação tem seu início quando o Estado passa a intervir na ordem econômica e se acentua quando da falência do Estado de Bem-Estar social. Esse é o escólio de Marques Neto (2002, p. 116): 
Tais processos adquirem grande impulso no período em que o Estado crescentemente passa a intervir na economia e assumir funções de provedor das necessidades sociais, explodindo a partir daquilo que diversos autores denominam de 'welfare state'.

O autor citado sustenta que se o Estado passa a não atender as demandas sociais, em que são crescentes, vai haver uma reação desta mesma sociedade num grau de organização maior para pressionar o pressionar por melhores condições. Esta reação, então, é fruto de demandas sociais que são crescentes, mais complexas, e que colocam o Estado numa posição de impotência. A conclusão de Marques Neto (2002) é que a sociedade vai se aglutinando em grupos de interesse, os quais se tornam espaços legítimos onde estão convergidos os interesses desses indivíduos e os instrumentos efetivos para atendimentos de suas necessidades. Ensina Marques Neto (2002) que o Estado, todavia, devido à falta de recurso, acolhe o interesse de alguns grupos e deixa de atender interesses de outros, o que faz surgir o desaparecimento da homogeneidade do interesse público.

Como exemplos dessa fragmentação podem ser citadas as organizações nãogovernamentais. Elas surgem nesse contexto, ou seja, a sociedade se organiza em grupos de interesse, e parcela desses grupos toma para si o encargo de realizar iniciativas concretas independentes de políticas governamentais. Disso se constata que a dicotomia público/privado é colocada à prova, pois, segundo Marques Neto (2002, p. 122): "Isso porque, embora construídas à margem do aparato estatal, seu raio de ação, abrangência dos interesses que perseguem e dependência de meios estatais dão a essas organizações um caráter publicizado”.

A partir disso se pode falar da relativização da unicidade do poder Estatal. Isso porque o Estado vai se relacionando com essa sociedade fragmentada. E este relacionamento ocorre, dentre outros meio institucionalizados, por meio das agências reguladoras. Contudo, essa relação é mais no papel de mediador dos interesses no seio da fragmentação. De acordo com Marques Neto (2002, p. 123): "Este papel é exercido fora dos parâmetros unilaterais que caracterizam o pode político no Estado Moderno.” É um papel contínuo, em que cabe ao Estado mediar e dialogar com os grupos de interesses da sociedade.

\section{OS FUNDAMENTOS DA REGULAÇÃO}

Neste item serão demonstrados os fundamentos da regulação, e para tanto serão utilizados os ensinamentos de Vital Moreira.

$\mathrm{Na}$ década de 1980 ocorreu uma mudança significativa na relação Estado/ Economia e também no que se refere à regulação econômica. Moreira, Maçãs 
(2003, p. 09) elencam dois os traços característicos dessa relação: "Por um lado, diminui o papel do Estado empresário e do Estado prestador directo de serviços públicos - é o que se chama desintervenção do Estado na economia”. Esta "desintervenção" significa que o Estado passa a ser regulador da ordem econômica que está submetida ao mercado. Com isso ocorre outro fenômeno citado pelo mesmo autor, o da "desgovernamentalização da regulação". Desgovernamentalizar a regulação, na visão do jurista português, significa despolitizar a regulação no sentido de distanciar a regulação de políticas governamentais e confiar a regulação a órgãos de Estado, que no caso brasileiro são autarquias que estão sob regime especial; as agências reguladoras.

Está-se a falar em reforma do Estado. Segundo Bresser Pereira a Reforma do Estado envolve quatro problemas. Para Pereira (1997), pode-se distinguir: um problema econômico-político, o qual envolve a questão do tamanho do Estado; um outro problema econômico-político, qual seja, a redefinição do papel do Estado regulador; um problema econômico-administrativo, qual seja, a recuperação da governança; e, por último, um papel político, ou seja, o aumento da governabilidade ou capacidade política do governo de intermediar interesses.

A necessidade de reforma do Estado advém da ascensão de uma crise econômica que teve curso nos anos 80 . Não constitui objeto de estudo as causas dessa crise, mas o que vale a pena ser registrado é que esta crise foi uma crise do modo de intervenção do Estado no domínio econômico. Segundo Pereira (1997, p. 9): “A Grande Depressão dos anos 30 decorreu do mau funcionamento do mercado, a Grande Crise dos anos 80, do colapso do Estado Social do século vinte". Como observou Bresser Pereira, a crise dos anos 30 se deu pelo mau funcionamento do mercado. Logo, a consequência foi a crise do Estado Liberal. Estavam criadas, assim, as condições para a emergência do Estado SocialBurocrático (expressão esta usada por Bresser Pereira), com o reconhecimento do papel complementar do Estado no domínio econômico.

Moreira e Maçãs (2003, p. 10) elencam mais duas mudanças na relação Estado/Economia que são importantes para este artigo: a primeira atinente "[...] à passagem de uma regulação hostil ao mercado para uma regulação constitutiva e fomentadora do mercado ('amiga do mercado'), mediante a liberalização e o fomento da concorrência”. Constata-se que os autores enaltecem o valor livreiniciativa como valor supremo da ordem econômica mundo do "dever ser". A segunda diz respeito à mudança para uma regulação voltada ao interesse público. 
O Estado passou a regular os setores abertos à iniciativa privada que passaram a estar sujeitos às regras de mercado e de concorrência. Com os processos de liberalização e privatização houve o que Moreira e Maçãs (2003, p. 13) chamaram de "apagamento da esfera econômica pública e do papel econômico do Estado". Logicamente ocorre o processo inverso com o "papel da regulação pública da economia”, em que o Estado, nos setores de prestação de serviço público, ou seja, setores de "interesse económico geral”, deve proteger interesses gerais e garantir a concorrência. Logo, Moreira e Maçãs (2003, p. 14) entendem regulação:

[...] como a capacidade para o estabelecimento de normas, garantir a sua aplicação e execução, bem como fiscalizar o cumprimento e efectivar a punição das infracções às referidas normas", ou seja, são as funções normativa, executiva e "parajudicial.

A nova regulação é aquela voltada ao mercado (pró-mercado), ou seja: é aquela que não impõe regras contrárias à dinâmica do mercado. A nova regulação, nas palavras de Moreia e Maçãs (2003, p. 15), visa "tão só fixar regras gerais e garantir a sua aplicação de uma forma neutra e independente”.

Estas características foram transportadas a outros Estados junto com a gênese da concepção de Agências Reguladoras Independes nos Estados Unidos da América. Basicamente são duas as razões justificadoras de tais Agências: a primeira característica, segundo Moreira e Maçãs (2003, p. 17) é que a criação dessas autoridades reguladoras independentes "[...] deveu-se ao compromisso de, por um lado, ter de haver regulação e, por outro lado, dever-se manter a economia livre da ingerência do Governo”. A segunda razão, ainda segundo Moreira e Maçãs (2003, p. 17):

Considerando a tradicional desconfiança do Congresso em relação ao Presidente, e para evitar que este acumulasse prerrogativas susceptíveis de afectarem o equilíbrio de poderes, o Congresso votou-se à criação de autoridades administrativas não sujeitas ao controlo do Presidente, enquanto chefe do executivo e da administração federal.

Vê-se, então, que estas agências possuem independência em relação ao Presidente. Devido ao seu alto grau de independência e suas funções, parte da doutrina europeia qualifica que tais autoridades são expressão de um "quarto poder”.

A regulação independente possui uma racionalidade comum a todos os países por onde houve a expansão das autoridades reguladoras independentes, guardadas o grau de tradição da livre iniciativa em cada Estado. Tal racionalidade é explicada por Moreira e Maçãs (2003, p. 21-22): 
Podemos dizer que independentemente das diferenças históricas e políticoinstitucionais, a expansão das ARI tem subjacente duas ideias comuns aos vários países, no seguimento da substituição do paradigma do Estado intervencionista pelo actual paradigma da 'economia de mercado regulada':

- primeira, o reconhecimento de que o mercado nem sempre dá garantias de bom funcionamento da economia, pela sua incapacidade de auto-regulação de modo eficaz e que o próprio mercado precisa de ser ele mesmo constituído e fomentado pela regulação, quer remediando os defeitos do funcionamento do mercado (market failures), quer fazendo valer valores sociais eminentes, nomeadamente no caso dos serviços públicos ou 'actividades de interesse económico geral'.

- segunda, o reconhecimento de que a regulação tem uma lógica especifica, que deve ser separada tanto quanto possível da lógica da política propriamente dita, de modo a conferir-lhe estabilidade, previsibilidade, imparcialidade e objectividade.

Com relação à segunda idéia há subjacente a proteção dos direitos dos administrados às investidas da atuação governamental. Nesta esteira há que se frisar os direitos básicos dos administrados, quais sejam, os direitos à transparência e o direito à informação propugnados por Salomão Filho (2008).

Podem-se estabelecer, então, as notas características da regulação na figura das autoridades administrativas independentes. As características essenciais são a independência, a neutralidade e a imparcialidade.

A característica da independência possui um ponto nodal, qual seja; os titulares dessas agências não podem ser exonerados pelo executivo antes do término dos seus respectivos mandatos. Outra faceta da independência se refere ao fato dos seus titulares não serem originários da Administração Pública, ou seja, os titulares devem ser pessoas cujo critério de escolha é a aptidão técnicoprofissional. Outra nota da independência se refere à independência funcional de tais entes, isso significa que a atuação de tais entes não sofrerá controle de mérito por parte da administração central. O controle hierárquico do poder executivo não atinge as autoridades administrativas independentes. Isso não significa, contudo, que ela não sofra qualquer tipo de controle, o qual fica a cargo do poder judiciário. Há, contudo, outra face da independência, qual seja, a independência em relação aos interesses envolvidos na atividade regulada para não ocorrer o fenômeno da captura das agências reguladoras.

Outra característica é o da neutralidade política da gestão das autoridades administrativas independentes. Aqui o ponto nodal reside no fato de as decisões dos agentes serem decisões técnicas, isentas de cunho político-partidário. Para tanto, segundo Moreira e Maçãs (2003, p. 29), “[...] a escolha dos titulares dos seus órgãos deve atender a critérios estritamente técnicos, recaindo sobre 
pessoas com elevada preparação científica e técnica, constituindo uma espécie de <<governo de sábios〉> ".

Como última característica há que citar a imparcialidade. Segundo Moreira e Maçãs (2003, p. 30): “Actuação administrativa imparcial significa um poder-dever dirigido à Administração no sentido de valorar e ponderar todos os interesses em jogo (públicos e privados) sem privilegiar ou discriminar qualquer deles”.

A constitucionalidade das autoridades administrativas independentes é questionada por parcela da doutrina europeia. O questionamento se assenta no fato de a independência dessas autoridades ferir os princípios da subordinação da Administração ao Executivo e da responsabilização do Executivo perante o poder legislativo. Segundo Moreira e Maçãs (2003), em sua gênese, são entes não sujeitos ao poder hierárquico ou controle do Executivo, o que quebra, todavia, a unidade da organização administrativa tradicional. A parcela doutrinária que não entende haver inconstitucionalidade dessas autoridades se fundamenta no fato de a legitimidade dessas não derivarem da sua dependência em relação ao executivo responsável perante o Parlamento. Pelo contrário, como bem explicam Moreira e Maçãs (2003, p. 45): “A legitimidade das AAI encontra-se [...] na sua própria estrutura, indissoluvelmente ligada à função que desenvolvem: regular de forma neutra um sector de actividade econômica e proteger o exercício real de liberdades públicas”. Então, para os críticos doutrinadores europeus administração independente significa desresponsabilização do Governo pelo setor regulado. Logo, a independência em relação ao governo significa independência em relação ao parlamento, o que significa carência de legitimidade democrática. Contudo, a análise da legitimidade deve derivar daquilo que Moreira e Maçãs (2003, p. 47) chamaram de "democracia procedimental", e prosseguem com a seguinte afirmativa:

Segundo alguns autores, a natureza das suas competências, o modo como as AAI actuam na prossecuação dos interesses coletivos e se relacionam com os cidadãos, grupos de interesses e operadores econômicos, conferem-lhe uma particular legitimação.

Vê-se, então, segundo os ensinamentos dos autores portugueses, que a reflexão sobre a legitimidade dessas entidades independentes não deve partir da democracia política, mas sim da democracia procedimental, ou seja, da capacidade de mediar interesses. É assente que o procedimento garante o contraditório, a transparência e a participação de todos os envolvidos nas decisões das autoridades administrativas independentes, o que traz benefícios aos regulados e às entidades reguladoras. Consta-se que esta questão da legitimidade das entidades reguladoras é controvertida na doutrina espanhola, e quem 
contesta tal legitimidade assevera que a proliferação de tais entidades significa o governo dos sábios. Feitas essas breves considerações sobre os fundamentos da regulação, cabe no próximo item demonstrar a noção de serviços públicos após a reforma do Estado.

\section{A NOVA NOÇÃO DE SERVIÇO PÚBLICO}

Este breve item tem por objetivo demonstrar a nova noção de serviço público.

Os serviços públicos neste artigo analisados são os serviços públicos ditos econômicos. O serviço público foi concebido por sua natureza e por força de lei como pertencente ao monopólio Estatal. Essa concepção começa a ser modificada a partir da década de 80 , em que o serviço público começa a ser caracterizado como espécie de atividade econômica. O Direito pátrio começou a positivar esta mudança no regime jurídico dos serviços públicos por meio da lei de concessões e permissões de serviços públicos (Lei n. 8.987/95), em seu art. 16. Segundo Aragão (2008, p. 411-412):

É nesse sentido que se pode falar de uma mudança na tradicional idéia de regulação dos serviços públicos, existentes no Brasil desde o surgimento das concessões até a década de oitenta, em que tínhamos uma regulação eminentemente contratual (através do contrato de concessão), sobre apenas um agente (o concessionário exclusivo) e com a concepção de que a atividade fora inteiramente retirada do mercado para ser titularizada como serviço público.

Hoje, ao revés, estamos diante de uma regulação de serviços públicos na maioria das vezes incidente sobre mais de um concessionário, evitada que é a outorga de direitos exclusivos, abrindo-se em alguns casos a atividade para agentes econômicos que podem vir a prestá-la fora do regime de serviço público e com a perspectiva de que o mercado não é excluído da regulação, sendo, outrossim, por ele atraído e a ele integrado.

Vê-se, assim, que, se sempre existiu e continua existindo a regulação dos serviços públicos delegados à iniciativa privada, a inserção de mecanismos concorrenciais alterou significativamente o seu substrato e o espírito que a anima, com incontornáveis reflexos na interpretação das suas regras e na forma de sua aplicação dos paradigmas tradicionais das delegações de serviços públicos (cláusulas regulamentares, jus variandi da Administração Pública, equação econômico-financeira etc)

A noção de serviço público sofreu influência das reformas pelas quais passaram os Estados ocidentais principalmente na década de 1990. Justen Filho (2003) atenta para o fato de que a nova configuração do serviço público apresenta como característica fundamental a extinção de monopólios. A explicação dessa característica é evidente; a ausência de concorrência. Para Justen Filho (2003, p. 38): 
Reputa-se que a intervenção regulatória estatal é insuficiente ou inadequada para gerar a ampliação da eficiência econômica indispensável à prestação de serviços adequados. A melhor alternativa é reduzir a intervenção estatal e ampliar os mecanismos de competição, que são o instrumento mais satisfatório para produzir eficiência.

Os monopólios, tanto estatal como privado, são indesejáveis numa economia de mercado, ressalvados os casos de monopólio natural. Essa conclusão pode ser extraída da própria lei antitruste ao não considerar ilícito o monopólio natural. Daí a implantação da competição.

De acordo com o art. $16^{1}$, da lei n. 8.987, as concessões e permissões, em regra, se darão com ausência de exclusividade. Conforme o dispositivo, a exclusividade se dará no caso de inviabilidade técnica ou econômica.

Outra observação digna de nota é com relação à possibilidade de fragmentação do serviço público. Como faceta da evolução da concepção do serviço público é possível fragmentar em vários núcleos a atuação do fornecimento dos serviços, com tratamento jurídico diversos. Um exemplo claro de onde há a fragmentação, citado pela doutrina, é o fornecimento de energia elétrica, em que há a atividade de geração, transporte e distribuição. Aqui é possível, técnica e economicamente, haver competição na geração de energia. Já com relação à transmissão via redes não é viável economicamente haver competição.

$\mathrm{Na}$ inviabilidade de multiplicação de infraestruturas deve haver a chamada dissociação entre propriedade e exploração da rede. Não cabe ao proprietário da rede o monopólio de sua exploração. Aqui uma pluralidade de agentes econômicos irá compartilhar o uso da infraestrutura, dando ao usuário possibilidades de escolha.

Outra observação importante é a atinente ao dever de interconexão. Esse dever de interconexão significa que a concorrência só é possível na medida em que todos os potenciais competidores tenham acesso às redes. Para Justen Filho (2003, p. 43): "A admissão de soluções excludentes da interconexão apenas pode justificar-se em virtude de exigências técnicas ou em face de atividades de utilidade restrita a certo universo de usuários”.

Atenta a doutrina que a concorrência é privilegiada não porque há um exercício comparativo pelos cientistas de quem é o melhor, se o mercado ou o Estado. A supressão dos monopólios e a conseqüente abertura do mercado são

\footnotetext{
1 “Art. 16. A outorga de concessão ou permissão não terá caráter de exclusividade, salvo no caso de inviabilidade técnica ou econômica justificada no ato a que se refere o art. 5을 Lei."
} 
justificadas pela constatação dos benefícios que a concorrência proporciona à coletividade.

No item seguinte será analisada que a nova regulação deve ser voltada a proporcionar a concorrência, respeitados os objetivos e as funções dos serviços públicos.

\section{A PONDERAÇÃO ENTRE VALORES CONCORRENCIAIS E OBJETIVOS DOS SERVIÇO̧S PÚBLICOS}

Juan de La Cruz Ferrer (2002) atenta para o fato da criação de um novo entorno institucional para a concorrência, num contexto que ele chama de "neo-regulación”. A "neo-regulación" é fruto da definição de novos fins a se perseguir pela política econômica, a qual, segundo Ferrer (2002, p. 240), "[...] exige nuevos instrumentos de técnica jurídica”. A justificativa para o uso da expressão "neo-regulación” é, segundo Ferrer (2002), o fato de se regular novamente um setor a partir de fundamentos conceituais, de fins e de técnicas instrumentais completamente diferentes da anterior regulação.

$\mathrm{Na}$ "neo-regulación" vai haver aquilo que Ferrer (2002, p. 241) colaciona acerca da mudança da racionalidade regulatória, ou seja, "[...] la confianza en la dirección pública del sector se sustituye por la confianza en las libertades y en el mercado [...]". Os fins da "neo-regulación" são a promoção da concorrência com a garantia à continuidade e qualidade dos serviços. Aqui já há o primeiro esboço da compatibilização entre os valores concorrenciais e os fins dos serviços públicos.

Constata-se que a doutrina europeia, aqui representada por Ferrer, se refere à mudança de sentido da regulação. Essa mudança abarca o que eles chamam de uma regulação conforme ao mercado. E mais, uma regulação pensada para o funcionamento do mercado e não para alcançar objetivos políticos. Esse é o escólio de Ortiz (1993 apud FERRER, 2002, p. 242), em que a nova regulação é pensada, então, "[...] para favorecer el funcionamiento de los mercados y no para alcanzar objetivos políticos”. A regulação tem o objetivo de assegurar a qualidade do serviço prestado, proteger o usuário e defender a concorrência. E aqui cabe uma observação de Ortiz (1993 apud FERRER, 2002, p. 242), segundo o qual:

No irá mal recordar aqui, en médio de esta febre privatizadora que se extiende por todo el mundo, que la privatización no es tampoco uma panacea - um monopolio privado puede ser tan inifeciente como un monopolio público - y que el único garante de la eficiencia econômica es la competencia, acompañada por la dosis adecuada de regulación. 
Pelos ensinamentos dos professores acima citados, está-se diante de uma regulação a serviço do mercado, ou seja, a regulação propugnada não é a regulação substitutiva do mercado, senão promotora e incentivadora da concorrência e que irá compatibilizá-la com vistas a garantir os principais princípios do regime dos serviços públicos, quais sejam: continuidade, universalidade e não discriminação. Para Ferrer (2002, p. 244):

La base del crescimiento econômico, de la reducción de la pobreza y del aumento de la calidad de vida está en el desarrollo del mercado, y los fundamentos del desarrollo de los mercados se encuentran en un ordenamiento jurídico que reconozca y garantice los derechos de propriedad, la libertad de empresa y la libre contratación.

Ferrer está a reconhecer os direitos de propriedade no campo dos serviços públicos ditos econômicos. Constata-se, contudo, que a promoção da livre concorrência e do mercado não é o objetivo exclusivo, pois é imprescindível garantir os princípios do serviço público e outros objetivos de interesse social como a proteção do meio-ambiente, por exemplo.

Neste ínterim deve ser suscitada a questão da regulação para proporcionar o desenvolvimento, especialmente em contextos econômicos como o do Brasil. Segundo Vilanova (2003, p. 480):

A expansão Estatal [...] importa numa redução dos termos da equação liberal, indivíduo/Estado. Os direitos individuais, constitucionalmente discriminados, e só reduzidos, nos termos consentidos pela Regra Maior, mediante lei, e não por meio da norma regulamentar, direitos que dispõem de garantias também constitucionais e de garantias do direito do processo, que é lei secundando a Constituição, restringem-se notavelmente. Protege-se o uso da propriedade, mas reprime-se qualquer forma de abuso desse direito real; mantém-se o princípio da livre empresa, mas o Estado (coisa inadmissível no regime liberal) também assume função empresarial no sistema da produção; protege-se a liberdade de comércio, mas sem o descomedimento individualista da concorrência sem limites.

O ensinamento de Vilanova corrobora a proporcionalidade dos atos regulatórios do Estado, pois, pelo que ficou depreendido da citação, deve-se

${ }^{36}$ De certa forma, a posição adoptada está próxima do sistema que pode denominarse "sistema finalístico da adequada consideração dos interesses" e segundo o qual a sociedade deve satisfazer interesses de vários grupos de pessoas, ainda que, eventualmente, isso possa implicar o sacrifício dos interesses dos sócios e não obstante estes pesarem, em regra, mais do que os restantes.

${ }^{37}$ São exemplares as três hipóteses avançadas por Werder (1998, apud COUTINHO DE ABREU, 2007, p. 44; 2009, p. 304-5).

${ }^{38}$ Parece excluir esta última possibilidade (de satisfação dos interesses dos stakeholders) Meireles da Cunha (2009, p. 53-4). 
proteger a livre iniciativa, mas o Estado deve intervir para que coíba o abuso do poder econômico.

De plano há a necessidade de plantar uma questão: qual a profundidade do papel regulatório do Estado em economias em vias de desenvolvimento como a do Brasil? A primeira observação a ser feita é a necessidade de o Estado promover o processo de desenvolvimento nas economias ditas em desenvolvimento. Salomão Filho (2002, p. 38) diz que: "Dessas considerações emergem duas preocupações, uma de forma, outra de fundo. A preocupação de fundo estimula a indagar dos princípios que devem reger o esforço desenvolvimentista”. Disso, o autor citado elenca princípios que regem a regulação.

O primeiro princípio que pode ser citado é o princípio redistributivo. Segundo Salomão Filho (2002, p. 38):

O resultado mais saliente e incontestável da análise histórico estrutural é a convicção de que nos países subdesenvolvidos, alterações de demanda e não alterações no processo produtivo são os grandes elementos propulsores do crescimento. Consequentemente, não há justificativa para centrar a filosofia regulatória em torno da eficiência.

Isso significa, segundo Salomão Filho (2002), que a regulação deve ser voltada à redistribuição para expandir o consumo pela sociedade, ou seja, é a ideia da associação do desenvolvimento econômico e distribuição dos seus frutos. A redistribuição é forma de dar eficiência ao Estado. Ainda segundo Salomão Filho (2002), o Estado deve pautar sua gestão não em objetivos estritamente econômicos. Há a redistribuição quando a prestação do serviço deve alcançar a todos os membros da coletividade por força do princípio da universalização dos serviços públicos.

O segundo é o princípio da "diluição dos centros de poder econômico e político e a conseqüente difusão de informações e conhecimento por toda a sociedade". Por este princípio há a concepção de que a governabilidade do sistema econômico é alcançada por meio da diluição do poder econômico. Parte-se do pressuposto de que a indução do desenvolvimento só é alcançável, segundo Salomão Filho (2002, p. 45), "com combate às condições estruturais da economia que favoreçam a concentração do poder e, portanto, a ingovernabilidade econômica". A regulação tem como fundamento, segundo Salomão Filho (2002, p. 46), "criar uma igualdade jurídica material, e não apenas formal, entre todos os agentes econômicos, e garantir a correção de seu procedimento no mercado".

Há, ainda, um terceiro princípio, que é o princípio da "cooperação". Tal princípio ganha importância especialmente numa seara em que prevalece o 
individualismo, que é o domínio econômico. A proposta de Salomão Filho (2002) é demonstrar a não oposição entre cooperação e o beneficio individual. O mote da cooperação é que, nas lições de Salomão Filho (2008), é do benefício público que deriva o privado, e não o contrário.

No ordenamento jurídico brasileiro os limites à atuação do Estado sobre a ordem econômica estão no art. 174, da CF. Este dispositivo prescreve a regulamentação da atividade econômica. $\mathrm{O}$ art. 174, caput, estabelece que o planejamento é determinante para o setor público e indicativo para o setor privado. Esta norma afasta o dirigismo do Estado sobre a economia. No entendimento de Salomão Filho (2008), afastado o dirigismo é necessário determinar a forma de intervencionismo propugnada pelo constituinte haja vista a competência normativa e reguladora do Estado ser ampla.

Esta amplitude, contudo, é reduzida pelo art. 170, da CF. Neste artigo constitucional estão os fundamentos, os fins e os princípios da ordem econômica. Estes fundamento e fins, segundo Salomão Filho (2008) constituem limites a qualquer fim a que pretende atingir um governo por meio de suas políticas. Mas há que se atentar para a hermenêutica deste artigo. Isso porque o art. 170, da CF, possui princípios que podem se conflitar, pois o caput do artigo positivou valores que a princípio são conflitantes, quais sejam: a valorização do trabalho humano e a livre iniciativa, voltados à realização da justiça social. É duvidosa, em princípio, a realização da justiça social por meio da livre iniciativa.

Este conflito, contudo, é dirimido mediante exercício hermenêutico. Logo, a questão deve ser analisada sob o paradigma do neoconstitucionalismo ou neopositivismo (esta última expressão a mais adequada). Em linhas gerais a constituição é composta por normas que se bipartem em regras e princípios. Segundo Guerra Filho (2001, p. 150), “[...] a Constituição, assim como todo o sistema de normas interno ao ordenamento jurídico, um sistema de regras e princípios”. Então há normas que são regras e há normas que são princípios. Os princípios passam a ter força normativa sob o paradigma do neopositivismo.

Esta observação acerca de regras e princípios é importante para a análise dos princípios do art. 170, da CF. Segundo Guerra Filho (2001, p. 150-151), distinguem-se regras e princípios também:

[...] pela separação 'onto-lógica' (rectius: 'deontológica') radical de ambos os tipos de normas, quando se tem, por exemplo, a possibilidade de princípios, em virtude de sua natureza, existirem implicitamente no sistema normativo, algo impensável para as regras, ou ainda a circunstância de regras contraditórias gerarem uma antinomia normativa, a ser desfeita com o afastamento de uma delas, ao passo que é da própria natureza dos princípios, como já salientamos, se apresentarem como contrapostos uns aos outros. 
Esta característica de colisão em que se encontram os princípios requer, segundo Guerra filho (2001, p. 151), “[...] o emprego dos princípios da interpretação constitucional, que passamos a expor, na formulação já clássica de Konrad Hesse, secundado, em língua portuguesa, por Gomes Canotilho”. E aqui pode ser evocada a proporcionalidade.

Neste ponto, então, cabe demonstrar a proporcionalidade a guiar os atos regulatórios do Estado. Segundo Guerra Filho (2001, p. 153):

Para resolver o grande dilema da interpretação constitucional, representado pelo conflito entre princípios constitucionais, aos quais se deve obediência, por ser a mesma posição que ocupam na hierarquia normativa, preconiza-se o recurso a um 'princípio dos princípios', o princípio da proporcionalidade, que determina a busca de uma 'solução de compromisso', na qual se respeita mais, em determinada situação, um dos princípios em conflito, procurando desrespeitar o mínimo o(s) outro(s), e jamais lhe(s) faltando minimamente com respeito, isto é, ferindo-lhe seu 'núcleo essencial'.

A análise que se faz neste artigo acerca da atividade regulatória do Estado é que pela proporcionalidade uma política econômica não pode substituir ou eliminar o sistema concorrencial. No âmbito dos setores regulados propriamente dito, segundo Aragão (2008, p. 424), "a restrição à concorrência só é admissível quando for meio idôneo para alcançar os objetivos constitucionais dos serviços públicos”. Uma política que elimine a concorrência de forma desarrazoada significa a supressão do princípio da livre iniciativa. As normas regulatórias como instrumentos de políticas sociais devem compreender o desempenho do serviço público de forma universal, o que significa que deve alcançar a todos. A universalidade pode justificar o sacrifício da concorrência quando tais objetivos afetos ao serviço público não puderem ser atendidos pela livre iniciativa. Segundo Aragão (2008, p. 426):

Para a combinação desses valores constitucionais em potencial conflito (necessidades dos serviços públicos versus concorrência), devem ser buscados, em um "mandado de otimização", os mecanismos que dêem a maior efetividade possível a ambos, o que, em um ponto ótimo, será alcançado através de políticas e medidas regulatórias que façam com que a concorrência seja o meio que melhor atenda aos interesses sociais dos serviços públicos.

Em assim sendo, o valor constitucional que deve prevalecer é o valor livre concorrência (art. 170, IV, da CF). É importante frisar que os valores em conflitos devem ser colocados na balança da proporcionalidade e, em se tratando de princípios, deve se conferir a eles, por meio de um mandado de otimização, a maior efetividade possível, conforme ensinou Alexandre Santos de Aragão. Este entendimento é demonstrado por Ortiz, García-Morato (2001), 
para os quais concorrência e regulação não são ideias contrapostas, mas sim complementares. Segundo Salomão Filho (2008, p. 166): “A obrigatoriedade de aplicação institucional do direito concorrencial e da regulação é, portanto, preemente". Prevalecer, contudo, não significa a eliminação dos objetivos de política econômica. A regulação, e aqui se pode falar tanto em regulação setorial como em regulação geral, deve ser analisada no contexto ao qual se insere. Num contexto como o do Brasil a regulação econômica deve se voltar também à perseguição de objetivos de política econômica de desenvolvimento.

A intensidade da regulação variará desde um grau menor, como a que ocorre nas atividades em regime privado (atividade econômica em sentido estrito), até um grau maior, como nas atividades reservadas ao regime de serviço público. Tanto nos serviços públicos como nas atividades econômicas em sentido estrito vai haver algum grau de incidência de regulação estatal. Como dito, o que irá variar é a intensidade da regulação. Mas em ambos o valor que deve nortear, num mandado de otimização, é a defesa da concorrência.

$\mathrm{Da}$ análise do principio da proporcionalidade conclui que se a regulação extrapolar no estabelecimento de regras, o ato normativo ferirá o princípio da proporcionalidade, padecendo, assim, de ilegalidade ou de inconstitucionalidade.

Uma observação importante, evocada por Silva (2010) e que calha ser feita, é que se verifica a tendência de setorização do direito antitruste. Mas há de se anotar com base em Silva (2010) que os setores regulados não estão alheios entre si e muito menos alheios aos demais setores da economia. O que não justifica a setorização do antitruste. A excessiva especialização dos setores pode levar aquilo que a doutrina chama de captura das agências reguladoras.

Neste contexto da "neo-regulación", cabe ao CADE e às agências reguladoras de serviço público uma nova postura. De acordo com Silva (2005, p. 5): "A questão não é a de simplesmente articular competências entre as agências e o $\mathrm{CADE}$, que de resto constitui apenas o primeiro passo neste processo, mas de inserção do Conselho na nova configuração regulatória do Estado”.

O princípio da concorrência se aplica a toda ordem econômica, indistintamente. $\mathrm{O}$ que irá diferenciar a aplicação do antitruste em setores regulados é a intensidade do direito antitruste. A relação entre regulação e a concorrência pode vir claramente estabelecida pelo marco regulatório, como ocorreu com a lei instituidora da ANATEL, Lei 9.472/97. Contudo, pode ocorrer de esta relação entre as autarquias não vir claramente estabelecida. Mas esta relação existirá, haja vista que tais setores estão em sintonia com os princípios informadores da Ordem Econômica. 
À atuação do CADE a das agências reguladoras, nos setores regulados, deve haver o sopesamento dos valores que norteiam estes setores com os princípios da ordem econômica. É nesta toada que Silva (2005, p. 11) desenvolve a ideia de "concorrência possível”, ou seja, "o antitruste é aplicável na medida em que não comprometa referidas finalidades regulatórias".

Este trabalho demonstrou que o valor concorrência deve guiar a atividade regulatória, mas há que se atentar para o fato de que a regulação econômica não se pauta somente pela ótica da competição. Em nome da universalização e da continuidade do serviço público, pode haver a preterição de um regime de concorrência plena. Este é o próprio entendimento do CADE no voto do Conselheiro Celso Campilongo no ato de concentração n. 08012.006762/200009:

Aliás, os aspectos específicos do setor serão obrigatoriamente sopesados pelo CADE quando da aplicação do Direito da Concorrência, abrindo-se "válvulas de escape" por meio da regra da razão. Aqui, o valor concorrência não tem aplicação tão mecânica quanto em setores "normais" da economia. O que se deve afastar, de plano, é a idéia de uma isenção antitruste para o setor financeiro. É possível que, em determinados setores da economia, a não incidência do direito da concorrência (controle de condutas e estruturas) seja parcial ou até mesmo total. Estes setores, dotados de características específicas (imperfeições estruturais, limitação de recursos, abertura à exploração, privatização, etc), podem ter substituídas a aplicação do controle das estruturas ou até mesmo de condutas pela utilização de mecanismos prévios de regulação.

O que se está a defender neste último item é a aplicação da proporcionalidade nos atos regulatórios do Estado. Esse posicionamento se sustenta porque a noção de atividade econômica adotada neste trabalho é a noção de Eros Grau, o qual classifica os serviços públicos dentro da atividade econômica em sentido amplo. Razão pela qual se aplica os princípios da Ordem Econômica insculpidos no art. 170, da CF/88 aos setores regulados. Silva (2005, p. 12) arremata este entendimento dizendo que: "Não se está aqui a advogar que as finalidades que sempre presidiram a noção de serviço público devam ser abandonadas, mas, justamente, que o seu alcance depende da idéia global de defesa da concorrência possível nestes setores".

Está-se a analisar neste artigo, em meio ao sopesamento dos valores constitucionais da ordem econômica, que a livre concorrência não deve ser menoscabada em face de objetivos regulatórios (regulação setorial). $\mathrm{O}$ princípio da livre concorrência não deve ser a exceção nos setores regulados, mesmo porque um valor não se reduz à exceção quando da aplicação da proporcionalidade.

Este artigo teve como referencial alguns autores de países da União Europeia. 
Essa opção se justifica pelo fato de que o direito europeu se orienta pelo reconhecimento da livre concorrência como um princípio orientador da ordem econômica. A doutrina europeia reconhece muito bem a nova articulação entre o serviço público e a economia de mercado. Os serviços públicos, como espécie do gênero atividade econômica, tendem a se submeter à lógica de mercado sem menoscabar os princípios orientadores dos serviços públicos tais como a universalidade e a continuidade.

Uma citação resume a questão proposta. Segundo Aragão (2008, p. 422), "se deve proceder à abertura ao mercado sempre que a concorrência ensejar uma satisfação desses objetivos de maneira melhor ou pelo menos igual à que propiciaria a prestação dos serviços públicos em regime não concorrencial”.

\section{CONSIDERAÇÕES FINAIS}

Como ficou demonstrado no artigo, pela proporcionalidade não se permite a supressão de princípios. Logo defender a concorrência no âmbito dos serviços públicos significa que a concorrência não vai se tornar um valor unicamente em si. A concorrência é viabilizada para ser um instrumento de difusão e boa prestação dos serviços públicos. Há, então, valores que devem ser sopesados, quais sejam: as necessidades sociais dos serviços públicos e a concorrência. Há que mencionar que a própria lei n. 8987/95, em seu art. 29, XI, já prevê o estímulo à concorrência.

Deve-se atentar que o grau de intensidade da intervenção estatal para a defesa da concorrência é diferente quando esta intervenção for sobre o domínio econômico em sentido estrito ou em setores regulados. Nos setores regulados há outras finalidades que convivem com a concorrência. Grande parte dos serviços públicos regulados não comporta concorrência plena como ocorre na atividade econômica em sentido estrito. Os serviços públicos são norteados por alguns princípios, como a da universalização e continuidade da prestação, princípios os quais nem sempre são compatíveis com os princípios concorrenciais, daí a ideia do sopesamento. Mas sempre estará presente o valor concorrencial no domínio econômico.

\section{REFERÊNCIAS}

ARAGÃO, Alexandre Santos de. Direito dos serviços públicos. 2. ed. Rio de Janeiro: Editora Forense, 2003.

FERRER, Juan de La Cruz. Princípios de regulacion económica en la Unión Europea. Madrid: Instituto de Estudios Econômicos, 2002. 
GRAU, Eros Roberto. A ordem econômica na Constituição de 1988. 13. ed. São Paulo: Malheiros Editores, 2008.

GARCÍA-MORATO, López de Castro; ORTIZ, Gaspar Ariño. Derecho de la competencia em sectores regulados. Granada: Editora Comares, 2001.

GUERRA FILHO, Willis Santiago. Teoria da Ciência Jurídica. São Paulo: Saraiva, 2001.

JUSTEN FILHO, Marçal. Teoria geral das concessões de serviço público. São Paulo: Dialética, 2003.

MARQUES NETO, Floriano Peixoto de Azevedo. Regulação estatal e serviços públicos. São Paulo: Malheiros, 2002.

MOREIRA, Vital; MAÇÃS, Fernanda. Autoridades reguladoras independentes: estudo e projecto de lei-quadro. Coimbra: Coimbra Ed., 2003.

PEREIRA, Luiz Carlos Bresser. A Reforma do Estado dos anos 90: lógica e mecanismos de controle. Brasília: Ministério da Administração Federal e Reforma do Estado, 1997.

SALOMÃO FILHO, Calixto. Regulação da Atividade Econômica (princípios e fundamentos jurídicos). 2. ed. São Paulo: Malheiros Editores, 2008.

. (Org.). Regulação e Desenvolvimento. São Paulo: Malheiros, 2002.

SILVA, Pedro Aurélio de Queiroz Pereira da. Direito da Concorrência e Regulação dos Serviços Públicos. Revista Eletrônica de Direito Administrativo Econômico, Salvador, n. 1, fev. 2005. Disponível em: 〈http://www.direitodoestado.com.br $>$. Acesso em: 03 de setembro de 2010.

VILANOVA, Lourival. Escritos Jurídicos e Filosóficos. São Paulo: Axis Mundi: IBET 2003. v. 2.

Artigo recebido em 21/05/11 e aprovado para publicação em 13/08/11 